\title{
Constrained Optimization for Addressing Forest-Wide Timber Production
}

\author{
Howard M. Hoganson • Natalie G. Meyer
}

Published online: 27 January 2015

(C) Springer International Publishing AG (outside the USA) 2015

\begin{abstract}
Optimization models are important tools for integrating objectives in forest management planning. Timber management objectives are difficult to address without considering complex environmental conditions, other ownership objectives, and forest management policies. Typically, to learn about management opportunities, model applications involve multiple scenarios and tradeoff analysis. Study areas tend to be large with analyses challenging because of model size needs for addressing many facets of the situation. The trend is to decompose large problems into linked subproblems with feedback between analyses. A better understanding of forest management situations can be obtained by integrating forest management decision-making with timber supply chain analyses developed from wood users' perspectives. Uncertainty surrounds forest management decision-making situations, with analyses expanding recently to address strategies for collecting forest inventory information and recourse opportunities to help reduce risks associated with an uncertain future.
\end{abstract}

Keywords Linear programming · Hierarchical planning · Shadow prices $\cdot$ Recourse $\cdot$ Decomposition $\cdot$ Operations research

This article is part of the Topical Collection on Integrating forestry in land use planning

H. M. Hoganson $(\triangle)$

Department of Forest Resources, North Central Research \& Outreach

Center, University of Minnesota, 1861 Highway 169 East, Grand

Rapids, MN 55744, USA

e-mail: hogan001@umn.edu

N. G. Meyer

Department of Forest Resources, North Central Research \& Outreach

Center, University of Minnesota, 115 Green Hall, 1530 Cleveland

Ave N, St Paul, MN 55108, USA

\section{Introduction}

From either a mathematical or forestry perspective, linear programming (LP) is a relatively new tool. The simplex method used to solve LP problems was not widely known until the 1960s [1]. In contrast, mathematics has been a study in its own right for thousands of years, and forest management planning dates to the 1500s in Europe. Yet LP-based applications for forest management planning have been around for about 50 years, and much has been learned and much has changed over that time. Some of the early forestry applications used supercomputers, while newer computer technologies have revolutionized abilities to solve large formulations on desktop computers. Early on, users realized the benefits of common terminology - model I or model II notation to describe formulations [2]. LP can address traditional forest regulation concepts like area control and volume control, as well as economic and ecological objectives. It can help support decisionmaking by simultaneously addressing multiple objectives over multiple forest cover types and multiple stand-level management intensities. With the forested land base generally limited and human populations and per-capita income rising worldwide, demands on forest resources are almost certain to increase. More has also been learned about important complexities of forests and potential changes in climate, making for greater concern over addressing environmental details in forest planning.

In the 1970s and 1980s, the USDA Forest Service invested heavily in emphasizing LP applications in forest planning, even when practical limits allowed only hundreds of unique forest management units and few integer variables. Early applications emphasized timber management with models often termed "harvest scheduling" models. In this article, focus will be on facets of forest management related to timber production, yet it is important to realize that applications can seldom address timber in isolation. Figure 1 shows some of the many 


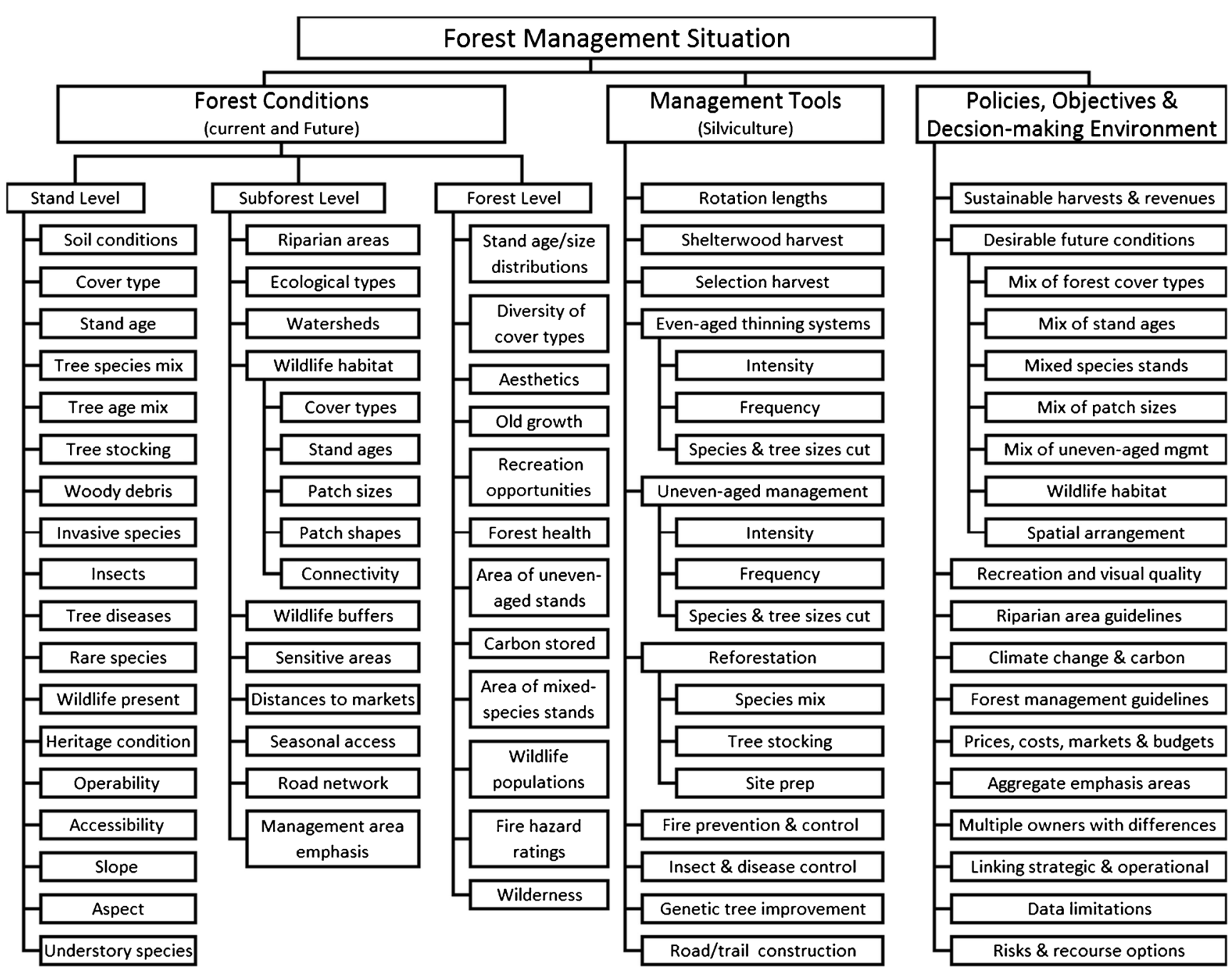

Fig. 1 Potentially important facets of forest management situations

facets of forest management problems. Many are complicated and not necessarily easy to represent well in a forest planning model.

This article provides a short summary of advancements, issues, and opportunities related to optimization modeling for addressing timber management in forest planning. Several recent forest management texts provide important detail and more background $[3,4,5 \bullet]$. We simplify our presentation by subdividing into subtopics, realizing that the subtopics are overlapping with other breakdowns plausible. Operations research is science based; yet, applying it well in forestry is often as much an art as it is a science. Our focus is on linear programming applications which assume (1) the constraints and objective function are linear in terms of the decision variables, (2) the values of the decision variables can be fractions, (3) responses to the variables are known with certainty, and (4) data needed for formulating the problem are available. Mixed integer programming (MIP) helps overcome situations where some decision variables cannot be fractions. MIP has been used extensively in forestry for addressing spatial detail. The simplex method for solving LP formulations provides shadow price estimates (also called dual prices or marginal costs) which describe the impact on the objective function of a per unit change in the right-hand-side value of each constraint in the model. Often, the value to use for right-hand-side values of constraints are questionable in forestry applications and represent management targets for timber production levels or future forest conditions. Shadow price estimates are often helpful in selecting specific target levels.

\section{Modeling Role Within Planning Process}

Forest management scheduling models are learning tools to support decision-making in planning. Most forestry situations have subjective elements surrounding management objectives. Especially for public forest lands, stakeholders seldom agree on a best model formulation, with multiple scenarios (alternatives) often modeled. For each scenario, planning teams strive to help develop the 
scenario to make it the best it can be. Scenarios are not simply "the industry alternative" or the "wilderness-user alternative." In the end, the public land management agency must be able to accept the alternative chosen and take ownership of it. The selection process for choosing a best alternative can potentially be quite political with the overall selection process beyond the scope of this review. Key output information for planning is often more than a specific mapped forest management schedule. For example, decision-makers are often interested in the costs of specific constraints and changes in forest conditions over time.

To help simplify analyses, organizations have often used a hierarchical planning process [6]. Typically, these divide problems up both spatially and temporally. In Sweden, often three temporal scales are used: a 100-year strategic plan, 10-year tactical plans, and 3-month operational plans. Multiple planning areas are often tied to a strategic plan that encompasses a substantially larger area [7].

Top-down hierarchical plans have potential weaknesses. At the top, the bottom-level information can be oversimplified, potentially leading to a less-than-optimal, top-level process passing down questionable constraints to lower levels. Improvements in optimization techniques coupled with faster computers and more available computer memory make simultaneous approaches a consideration [6].

In Finland, a bottom-up approach has been used with optimal regional solutions often not achieving country-wide goals; regions are large with substantial detail modeled. A difficulty in Finland has been in balancing regional concerns with national objectives. Integrated bottom-up and top-down approaches have shown promise [8]. A completely simultaneous approach would be challenged by model size and variations in objectives identified between regional stakeholders [8].

The USDA Forest Service has a longer history than most public forest management agencies in using operations research models in forest planning [9]. At one time, all national forests in the USA were required to utilize a harvest scheduling model in forest planning. Timber RAM [10], developed by the USDA Forest Service, was one of the first widely used timber harvest scheduling models. It focused on timber production with traditional forest-wide regulation constraints included to control (sustain) the area and/or timber volume harvested each planning period. With the USDA Forest Service, Timber RAM was followed by MUSYC [11], FORPLAN [9], and SPECTRUM [12]. US Forest Service Land Management Planning, based on its most recent planning rules, considers models as one of many tools available to inform the planning process [13]. While the use of models is encouraged, there are no explicit requirements for their use, nor are there guidelines in place for model selection and applications. The absence of direct policy regarding the use of models in USFS planning can be seen as a way to give land managers flexibility while helping avoid potential litigation.

\section{From Problem Situation to Problem Structure}

Operations research (OR) can help address forestry problems by recognizing that many fit a specific problem structure of OR - for example, a fit as a linear programming (LP) problem or dynamic programming problem. A key for success is keeping models simple enough to be useful yet complex enough to adequately describe the problem. Major shortcomings can result if a model solution is implemented when the model formulation does not represent the problem situation well [14]. It is important that users generally understand models. Yet as noted earlier, forestry problems are typically complex, with many potentially important facets making for complicated problem situations without clear best model formulations. Foresters and decision-makers are not trained in great detail in operations research, so understanding complex models is a challenge. Analysts may understand operations research well, but may not understand all the important facets of the forest management situation and their potential interactions.

Problem situations can be in terms of the forest landowner's perspective (forest plan), the wood user's perspective (timber supply chain), or society's perspective with concerns about economic development, sustainability, and environmental impact.

\section{Objectives, Constraints, and Demand Curves?}

Timber harvest scheduling models are economic models. Economic models can address resource allocations beyond those traded in the market. To many foresters and stakeholders, economics is thought of as the marketdriven financial facets of the situation. So it is understandable why "economics" can be viewed somewhat negatively at first by some in the context of forest management. Timber harvest scheduling models go beyond stand-level analysis by coordinating management of stands to address concerns about forest-wide resource flows and overall forest conditions. We refer to these concerns as forest-wide concerns, recognizing that some may involve only part of the forest.

Most optimization-based forest harvest scheduling applications in the USA have used an estimate of the net present value (NPV) of the forest in the objective function. Some applications simplify to maximize timber volume harvested [15]. The sensitivity of overall results to the choice of objective function is a critical consideration.

Typically, only one objective is included in the objective function, as it is difficult to assign relative weights for multiple 
objectives. Yet objectives are addressed only after all constraints in the model are satisfied. Constraints thus take priority. Forest-wide constraints might be included to move the forest toward long-term desired future conditions, limit the forest area (or volume) harvested each period, or keep scheduled activities within budget each period. Combinations of these forest-wide constraint types are often used, yet the total number of forest-wide constraints is typically small compared to the number of constraints needed to define management options for each of the many stands (or management areas) in the forest [2].

Questions often arise about whether an "objective" should be addressed in the objective function, or instead, in a constraint. A disadvantage of including an "objective" in a constraint is that once the constraint is satisfied, there is no explicit incentive to produce more than the minimum required. A potential compromise is to use a downward sloping demand curve (or marginal revenue curve) in the formulation. This suggestion has been made frequently by stakeholders for USDA Forest Service planning. A downward sloping demand curve recognizes that the per unit marginal value of a forest output (or condition) is less when more of the output is produced. For addressing an environmental condition, a demand curve is appealing in that it places a higher per unit value on the condition if it is relatively scarce. For timber market flows, demand curves help recognize the sensitivity of demand to price. The EConomic Harvest Optimization (ECHO) model emphasized demand curves $[16,17]$, suggesting that by modeling demand/price relationships, the forest will move toward a more balanced age class distribution without the need for evenflow constraints. Including downward sloping demand curves is relatively easy to implement and understand using a piecewise linear approach [18]. A demand curve can be included using just a single constraint [19]. Consider two extreme but commonly used cases for demand curves: (1) a horizontal demand curve; it represents the case where the output is simply valued in the objective function at a per unit price regardless of the output level, and (2) a vertical demand curve, the case where a constraint forces a fixed quantity of output regardless of price.

As noted earlier, the simplex method generates a shadow price estimate for each constraint included in the model. Each shadow price is an estimated rate of change in the objective function for a per unit change in the level of the constraint. To better understand LP model results, shadow price estimates for forest-wide constraints can be interpreted as per unit penalties or credits used in a stand-level economic analysis [20-23]. Shadow price estimates help show which constraints are costly and which can have their constraint levels adjusted with low impact on the optimal value of objective function. As we will discuss later, shadow prices can play a key role in decomposing large problems into linked subproblems.

Valuing ending inventory is potentially important, even in problem formulations with long planning horizons. With long planning horizons and discounting, ending inventory values may contribute relatively little to the objective function. However, the modeling solution process will do what it can to optimize when addressing ending inventory valuations or constraints. For example, the model could strive to liquidate much of the forest at the end of the planning horizon if ending inventory is not valued; at the other extreme, it could hold inventory beyond the end of the planning horizon if ending inventory is overvalued. Impacts are perhaps better understood if considered from a stand-level perspective and how net per unit timber values change over time due to the impacts of any ending inventory constraints [24].

\section{Addressing Large Problems}

Model formulations can become large rapidly as more facets of the problem are explicitly recognized. For many years, research in forest management has explored ways of overcoming problems of model size. Most agree that solving a single model formulation addressing all facets of the problem simultaneously would be most desirable. But in many situations, that is not possible. Substantial experience has been gained through work aimed at taking advantage of specific characteristics of forestry problems for decomposing large problems into parts with hierarchical linkages. While sequentially solved hierarchical models have contributed significantly to the handling of large forest management problems, shortcomings can arise when hierarchical models are not well-linked. Often, OR planning models are classified as strategic, operational, or technical with hierarchical linkages used between levels. However, even at the strategic level, problems can be too large to represent well within a model of practical size. Details at the stand-level are the building blocks supporting strategic planning, and unless those cornerstones are described well in a strategic model, it is difficult to have substantial confidence in how well it represents the problem.

Many harvest scheduling problems have an enormous number of stand types within the forest connected by relatively few forest-wide constraints. If the shadow prices for the forest-wide constraints are assumed known, then the problem can be decomposed into many independent subproblems, each representing a Faustmann analysis for one stand in the forest [22]. The Dualplan model is based on this subproblem structure and iteratively searches for shadow prices that satisfy the forest-wide constraints [20,21]. This type of approach has been applied operationally for each of two National Forests in Minnesota [25]. The process recognizes that shadow prices are likely serially correlated for constraints that differ only in 
terms of the planning period represented. The process also recognizes that most timber stands have potential to shift harvest timings by one or more planning periods without a large change in value. This implies that timings can be shifted to help overcome imbalances in resource flows or forest conditions. The shadow pricing feature provides a systematic way of addressing forest-wide constraints within a detailed stand-level analysis. The stand-level analysis can utilize dynamic programming so that enumeration of all management strategies is not necessary. The Dualplan model does not satisfy the forest-wide constraints exactly, but the solutions are optimal for the forest-wide near-feasible constraint levels produced [20]. Often, specific levels for forest-wide constraints are difficult to define precisely so near-feasibilities in those constraints are not a major concern.

The JLP model $[26,27]$ also takes advantage of the relatively few forest-wide constraints within harvest scheduling formulations compared to the number of constraints defining stand-level management options. JLP uses generalized upper bound techniques [28] rather than explicit constraints in an LP to define the area of each stand. Each pivot of the simplex method uses current shadow price estimates for the forestwide constraint to identify which model I stand-level variable is most profitable to introduce into the solution. It has advantages similar to the revised simplex method in that the size of the LP matrix is greatly reduced. The process also uses upper bound techniques to maintain feasibility of the forest-wide constraints. JLP has been used extensively in application in Finland, for both short-term and long-term planning. It is a key component of the MELA system, often considering tens of thousands of stands [29].

Another approach to coordinate strategic planning divides the forest into subforests, tracking modeled outputs for each subforest by period in a top-level strategic model [30]. Next, the tracked subforest output levels are used as constraint levels in separate models for each subforest. Some flexibility in output levels is allowed at the subforest level, recognizing that important facets of the subforest situation were not included in the strategic model [30]. The approach is intended to be run iteratively with feedback. For example, the subforest model could consider facets like road-building options with scheduled roads used as feedback for a revised formulation of the broader strategic plan. Overall, emphasis is on checks and readjustments to generally match solutions found between the modeling levels. A key is to reduce inconsistencies in results between the analysis levels.

Another more explicitly defined hierarchical model has been developed and tested where shadow price estimates of the forest-wide model are keys in linking models for each subforest [31]. Subforest problems use integer variables to address adjacency constraints, and solutions summed over all subforests can be used to approximate integer solutions for the forest-wide problem. Test case results have been impressive [31].

Concerns of oversimplified model formulations overestimating timber supplies are well recognized in the literature [31-33]. Oversimplifying may be in terms of leaving out important constraints or variables. For example, at one time, it was generally assumed in USDA National Forest Planning that adjacency constraints were needed, but were too complicated to include in forest-wide models. When managers then tried to map the solutions of nonspatial LP formulations, the harvest levels estimated could not be achieved. Oversimplifying may be in terms of hierarchical models that are not well-linked [34, 35]. In situations where an allowable cut is determined by a long-term model from a landowner's perspective and then that harvest level is assumed available in a wood user's short-term supply chain model, the implied management schedule can be quite different in the supply chain model, causing real drift of the forest over time. In effect, the associated estimated sustainable harvest levels will ultimately be unsustainable [35]. Substantial reductions in drift have been demonstrated by including demand expectation constraints for specific products in the short-term supply chain model. Similar reductions have been achieved in timber supply chain modeling that includes anticipation [36].

Another strategy with potential for simplifying large model formulations is to treat some constraints as lazy constraints - constraints that are unlikely to be binding. Detailed testing has suggested that this may be a good way to recognize spatial constraints [37•]. Essentially, lazy constraints are added to the formulation only after it is clear from intermediate solutions that the constraints are needed. Further savings in computation time are plausible through methods that may eliminate the need to enumerate and check all spatial constraints for feasibility. Treating some constraints as lazy constraints is somewhat similar to a simplifying approach that uses a branch and price method to overcome violations of adjacency constraints [38]. Similar to lazy constraints, the process recognizes that very few spatial constraints are likely to be binding for the optimal solution. An advantage of the lazy constraint approach is that algorithms for addressing lazy constraints are available in commercial solvers.

Although problems are large, the forest planning process needs multiple scenarios analyzed along with associated tradeoff analysis. Alternative methods for tradeoff analysis have been tested for identifying best solutions along an efficiency frontier of solutions involving two objectives [39] and three or more objectives [40]. An exact representation of the efficiency frontier is challenging when integer variables are involved [39, 40]. Strategic planning often leads to 
adjustments in model formulations as more is learned through the analysis process. Good interaction between analysts, planning teams, and decision-makers is a key to success [14].

\section{Large Study Areas with Multiple Timber Market Locations}

Often, it is important to consider forest management from a broader regional perspective involving multiple forest ownerships and multiple forest markets. For example, in decisions concerning the potential of a new timber mill, one can seldom look at an area surrounding a potential mill site and assume all timber in that area would be available to the new mill. DTran is an expansion of the Dualplan model that uses Lagrangian relaxation concepts to help address transport considerations and timber supply issues from a larger statewide or regional perspective [41]. Simple maps of timber procurement zones are used directly in the model solution strategy for each timber market and forest product. This eliminates the need to explicitly enumerate separate decision variables for every possible wood shipment strategy for each stand. As iterations adjust shadow prices for markets, procurement zone boundaries are adjusted in maps for each product and period. Shadow price estimates and the associated procurement zone maps for the markets are valuable when comparing solutions. DTran was used for a statewide generic environmental impact statement (GEIS) on Timber Harvesting and Management in Minnesota [42]. For the GEIS, a broad statewide perspective was desired to help address the potential opportunities of mill expansions and the impacts expansions might have on timber supply and statewide environmental conditions. An ongoing study is updating DTran and developing a new statewide assessment.

The JLP model has also been updated to address large areas involving multiple timber markets [43•]. It separates and then links the market destination decisions from specific model I decision options for each stand. This overcomes the need to enumerate all possible shipping options as unique model I decision variables. Similar to the constraints defining the area and management options for each stand, the constraints defining product shipment volumes are moved to the objective function and handled using generalized upper bound techniques. Overall, the modeling approach is similar to the DTran model as it takes advantage of the special structure of the LP formulation. The updated JLP model can meet forest-wide constraints exactly. The mathematics are impressive with full understanding of the specific details not critical to its application.

Optimization-based forest sector models have been used substantially to look at timber supply and demand interactions between large regions or countries. Optimal control theory is used to find optimal, market equilibrium, inter-temporal solutions between regions [44]. A recent review of forest sector models describes their primary purpose as scenario analysis, highlighting impacts of estimated changes in the forest resources over time [45]. Generally, these models do not track individual stands specifically.

\section{Timber Transport Planning}

Transport costs are a substantial component of wood supply costs and are sensitive to fuel prices. A need for better linkages between forest planning models and timber supply chain modeling is recognized for improving forest planning [33]. Timber transport costs are typically quite variable between stands, with some stands involving long haul distances. Sorting yards are also common, especially in areas with mixed species stands. Furthermore, seasonal differences can be a major concern, with some roads and stands available only during dry conditions or with frozen ground.

Mixed integer programming (MIP) has been used to synchronously estimate monthly production levels, harvest areas, and market prices for a study area in Sweden. The study involved, timber logs, biofuel residues, multiple market locations, and detailed estimates of harvest and transport costs over 12 planning periods [46]. The intensity of harvest was allowed to vary depending on demand for forest residues. Results suggested that a synchronous approach leads to better solutions than a sequential approach.

Recent work has shown substantial opportunities to lower wood procurement costs by coordinating timber procurement through forming coalitions between mills to help reduce total transport costs [47, 48]. Methods to achieve this have used MIP and column generation techniques [49]. Shadow price estimates from the model are used to define best backhaul opportunities. The column generation technique overcomes the need to explicitly enumerate an enormous number of backhaul options. As expected, full collaboration results in the lowest-cost solution [48], yet not all mills are likely to be willing participants. Results showed substantially smaller incremental gains from a coalition as limits on the number of coalition members are increased. Savings depend on forest land ownership patterns in the region and timber pricing policies.

\section{Recognizing Uncertainty}

Forest management involves long production periods and complex biological processes. Yet to help keep most forest management scheduling models simple, deterministic models have typically been used. It is suggested that incorporating risk and uncertainty is crucial for forest planning [33]. Historically, policies directing public forest management use phrases like "keep options open" and "avoid irreversible mistakes." It 
is important to question the value of optimal solutions to simplified formulations that assume the value of model parameters are known with certainty. Ideally, managers would like recourse in plans, identifying what to do under a range of plausible futures. Essentially, one would like to plan a few moves ahead, considering impacts of immediate decisions on options or moves available as the future unfolds.

Uncertainty in forest planning does not only involve uncertainty about the future. Large amounts of data are used as input to planning, much of which describes the existing condition of the forest. Perhaps, it would pay to collect more forest inventory information for making short-term decisions. Perhaps, collecting inventory information could even be scheduled in the forest management scheduling process much like the model schedules a harvest or regeneration activity.

\section{Collecting Inventory Information}

Forest inventory information is key input data for timber harvest scheduling. Collecting forest inventory data is often a relatively large forest management expense, with questions raised about how intensively to inventory. In the USA, it is not uncommon for forest planners to use stand-level inventory information that is ten or more years old. Relatively little is known about the impact of uncertainty or imprecision surrounding the information on forest management planning. Typically, in forest planning models, it is assumed that the coefficients of the model are known with certainty. For inventory design, a common approach is to minimize "cost + loss" where cost is the cost of the inventory and loss is the loss in value of decisions made from not having perfect information [50]. It is suggested that this provides a more rational way for developing forest sampling strategies, because the primary reason for more accurate forest inventories and yield model predictions is to produce better management decisions. The question of best inventory strategy fits reasonably well into a timber harvest scheduling framework, where optimal LP solutions can be compared for formulations that differ in terms of the inventory estimates upon which they are based [51•]. Tests can involve both inventory information describing stands and inventory information collected to develop growth models [51•]. Detailed case study tests for radiata pine in Chile suggested large gains from intensifying stand-level inventory samples while reducing sampling for developing growth models [51•]. To help overcome problems with meeting constraints exactly, deviations in constraints were moved to the objective function and penalized using estimates of shadow prices for those constraints. Overall, results strongly suggested that it is more important to have knowledge of the forest inventory than to improve yield projection models; relatively good growth and yield models were developed without intensive sampling.

For addressing inventory design from a forest planning perspective, there is potentially more important detail to examine with an LP-based approach. Optimal sampling intensity likely varies substantially between stands. Large gains are plausible by delaying inventories and combining them with follow-up, intensive inventories often done as part of sale preparation - after management decisions have been made. It is likely that delaying these inventories will substantially improve information about the harvest decision while also delaying inventory costs. After decisions are made, needed information for implementing timber sales can be made using inventory projection methods as long as projection periods are relatively short. Some landowners have timber sale practices where timber prices are contingent on actual yields, making precise estimates of volumes less important at time of sale.

The value of obtaining more inventory information has also been examined from the perspective of timber buyers [52]. A stochastic programming approach was used considering both a budget constraint and a timber demand constraint. One hundred possible uncertain outcomes were addressed in a single period model. Questions focused on which stands to purchase with uncertain inventory information and the expected loss from the lack of perfect information.

A "cost + loss" system for linking planning with inventory has been proposed for considering options to gather more information before decisions on plans for short-term operational plans are made [53]. Planning was viewed as a continuous process with re-planning of a 10-year tactical plan occurring every year. Operational planning used two annual planning periods. The option to collect more inventory data for selected stands is available before applying the operational plan each year. Results of the operational plan provided feedback to a new 10-year tactical plan, and the entire planning process can be simulated through time. Tests of representative real-world conditions showed substantial gains from additional inventories. Gains would likely be even larger if long-term benefits of the added inventory information could be recognized [53].

\section{Planning Under an Uncertain Future}

Recognition of an uncertain future (multiple futures) can fit an LP structure where stand-level decision trees are expanded to describe different futures [54]. A simple two-stand forest was used to illustrate how the problem can be described using stand-level decision trees, much like how dynamic programming networks are used to describe stand-level decision options. The formulation is similar to that used in modeling timber supply recognizing risks of forest fire [55]. Uncertainty 
about the future unfolds through multiple stages of the formulation. Probability estimates describe likelihood of each outcome associated with the stochastic branches of a stand-level decision tree. This type of approach is termed planning with recourse [1]. It is suggested that this method of recognizing uncertainty would fit well with decomposition approaches [54]. A desire to consider multiple futures was an underlying reason for developing the Dualplan model [20]. Early applications merged model formulations, one for each future, and forced schedules in the first stage to be identical for all futures of a second stage [56]. Applications succeeded in recognizing a realistically sized forest, but the sensitivity of first-period schedules to the length of the first stage was of concern. With a short first stage, models tended to "wait out" investment decisions until it became clear that such investments are profitable. A four-stage application to recognize timber management strategies under risks of insects allowed uncertainty to unfold more gradually over time [57]. As one would expect, the value of preventive treatment options is greater when a range of futures is considered. Forest management options

Table 1 Forestry decision support systems utilizing optimization techniques [66, 67]

System Details

Agflor (Agro-forestry DSS)

Tech. Univ. of Lisbon, Portugal [68]

FPS (Forest Projection and Planning System) Forest Biometrics Research Inst., USA [69]

\section{Habplan3}

Nat.1 Council for Air and Stream Improvement, USA [70]

Heureka Forestry DSS

Swedish Univ. of Agricultural Sciences [71, 72•]

MELA

Finnish Forest Research Inst. [29]

\section{MONSU}

Timo Pukkala and Heikki Parikka, Finland [64]

SADfLOR/SADfLOR web-based Inst. of Agronomy, Portugal [5•, 73]

SIMO (Simulation and Optimization) Univ. of Helsinki, Finland [65]

Spectrum

USDA Forest Service [12]

SFMM (Strategic Forest Management Model) Ontario Ministry \& AIMMS [74]

Woodstock and Stanley

Remsoft, Canada [75]
Input: Vector-based GIS information to display management units and economic data, policy changes, product prices, supply elasticity, and subsidies

Output: Reports of changes in area used for various agricultural activities, agricultural production, and revenues; both maps and tables are provided

Input: Stand-level forest inventory with GIS linkages, specification of treatment options, goals, and constraints; provides growth and yield models for all stand structures based on extensive regional inventory data

Output: Optimization solution reports and an interactive GIS database

Input: Allowable management regimes for each spatial unit; user interface facilitates building an objective function and constraints

Output: Graphs of flows of goods and services including target minimum and maximum levels; GIS viewer displays management regimes for each polygon and custom queries

Input: Tree-level or stand-level inventory data; a mobile application (Ivent) to facilitate field inventory is available; also supports input of data from outside sources

Output: Interactive maps, tables, ranked lists of optimal management alternatives, growth projections, treatment simulations, non-timber value measurements

Input: Tree-level inventory data, temporal specifications, management actions and objectives; the MELA handbook provides information on input methods

Output: The optimization module generates forest-level solution, management schedule, shadow price and cost of change reports, and forest-level summary data; uses JLP solver

Input: Tree-level inventory data (including dead trees), specification of management goals and weights; geographical data must be provided for use of the visual interface

Output: Final forest management plan report, visual interface for analysis of weights on the optimization solution, landscape visualizer to display the forest management plan

Input: Plot-level inventory data with the INfLOR module, management alternatives with the SAGfLOR module, specification of objective function and constraints

Output: Optimization solution reports provided in various formats including tables, graphs and maps; non-web-based version offers a GIS visualization tool

Input: Text files of numerical and categorical data, specific syntax to define objective functions, weights, and constraints; optional geographical data for on-line GIS feature

Output: Growth and yield simulation data and operation results variables (eg. cut timber assortment volumes, cash flow) available in various formats; uses JLP solver

Input: Temporal specifications, management options for land units, objective equations, and yield data from the Forest Vegetation Simulator or comma-delimited files

Output: Formatted reports, comma-delimited files, or tables of alternative management pathways, and economic and environmental tradeoffs

Input: Takes advantage of Advanced Interactive Multidimensional Modeling System (AIMMS) features including graphical user interface and infeasibility finder

Output: Pivot tables and colored highlighting to aid interpretations. Free viewer license for improved sharing of outputs with stakeholders. AIMMS Tech support

Input: Landscape themes, development types, management actions or natural events, transitions, yield components, and outputs (to be reported or controlled in the model)

Output: Defined by user in LP model objective function, solution report will be in the format of solver software used 
for the near term to address insect, disease, fire, or climate change concerns are potentially undervalued substantially if only considered under an "average" future.

A robust optimization model approach has shown substantial potential for addressing randomness in model coefficients of LP formulations of forest management scheduling problems [58]. The idea is to find high-value solutions that are much more likely to satisfy constraints regardless of the true values for the uncertain coefficients. Focus was on uncertainty surrounding timber yield estimates and minimum production levels per period. Simulating results of repeating this schedule process over time showed substantial increase in likelihood of satisfying constraints with only a modest decrease in net present value. The process has also been applied successfully to address road-building decisions with opportunity to examine tradeoffs between expected return and robustness in satisfying key forest-wide constraints [59].

\section{Current Decision Support Systems}

As the size and complexity of forest management problems increase, the development and use of systems to aid in the decision-making process continue to be essential. Decision support systems (DSS) have evolved alongside forest management for nearly three decades, providing decision-makers with a process to define forest management problems and investigate alternatives [60]. In their early days of development, DSS handled small problems focused on optimizing timber production and revenue. Today, advancements in technology and the recognition of non-timber forest benefits have spurred the development of a diversity of more complex and robust DSS [61]. As a technical definition, a forest DSS is a computerized tool containing systems for data management, growth and yield modeling, and problem processing $[5 \cdot, 60]$.

In the greater realm of DSS science, there are five categories of DSS: model-driven, communications-driven, datadriven, document-driven, and knowledge-driven. Modeldriven DSS contain an architecture focused on the model component, making them the most common type applied to forest management [62]. A popular model type within modeldriven DSS is optimization, used often in revenue and yield management [62]. Within the forestry context, optimization techniques have been widely used for traditional problems regarding optimal stand-level treatment options. More recently, they have been further applied to much larger problems addressing multiple stands and the integration of several objectives, including spatial and ecological objectives [63]. Table 1 provides a list of current DSS most commonly used by forest managers and researchers that include optimization techniques as part of their problem processing systems.
Substantial progress has been made in forest DSS development in Scandinavia, where some of the most comprehensive DSS have originated. Of particular note are the Finnish models MELA, Monsu, and SIMO. MELA emphasizes the synthesis of stand-level management planning and forestwide production planning in the optimization problem [29]. Rather than addressing multi-level spatial objectives, Monsu is a forest-level DSS developed to aid in multiple-use forest planning. Monsu addresses variables beyond timber production such as berry and mushroom yields and recreation scores [64]. SIMO takes an entirely different approach to decision support, featuring a flexible data model that allows the user to build their own growth and yield models and, using optimization methods, apply them to a variety of planning problems [65].

There is a vast diversity of DSS available to forest managers worldwide. Table 1 addresses a mere sampling of them and illustrates how different each can be. A comprehensive list can be found through the ForestDSS Community of Practice [66].

\section{Conclusions}

Progress has been made in developing management science tools to help support forest planning. Yet there is much more that can be done. Each forest planning situation is unique. Most situations have many complicating factors, making modeling of multiple scenarios a sound strategy. This may complicate planning, but much is usually at stake. Uninformed decisions will have high potential to lead to poor management choices. There is no doubt as to why operations research is described as "the science of better."

Site-level detail is important for most forest management situations. Yet it is also desirable to encompass large areas and long planning horizons because of the many interacting facets of the situation. Subdividing overall problems into well-linked subproblems has shown substantial promise, yet it is a challenge for foresters and decision-makers to understand and apply large modeling systems well; understanding linkages between submodels is essential. An important step in planning is to present what can be learned; explaining a model's selected solutions and tradeoffs. There is often much at stake, perhaps far more than many decision-makers and stakeholders realize.

\section{Compliance with Ethics Guidelines}

Conflict of Interest Dr. Hoganson and Natalie Meyer both state that they have no conflicts of interests to declare.

Human and Animal Rights and Informed Consent This article contains no studies with human or animal subjects performed by the author. 


\section{References}

Papers of particular interest, published recently, have been highlighted as:

- Of importance

1. Dantzig G. Linear programming and extensions. Princeton: Princeton Univ. Press; 1963. p. 625.

2. Johnson K, and Scheurman H. Techniques for prescribing optimal timber harvest and investment under different objectives-discussion and synthesis. For Sci Mono. 1977;(18): 31.

3. Bettinger P, Boston K, Siry J, Grebner D. Forest management and planning. Burlington: Elsevier Academic Press; 2009. p. 331.

4. von Gadow K, Pukkala T, editors. Designing green landscapes. London: Springer; 2008. p. 286.

5. Borges J, Diaz-Balteiro L, McDill M, Rodriguez L, editors. The management of industrial plantations: theoretical foundations and applications. London: Springer; 2014. p. 543. A comprehensive and current syntheisis of forest management, emphasizing quantitative methods and decision support systems.

6. Eriksson LO, Wahlberg O, Nilsson M. Questioning the contemporary forest planning paradigm: making use of local knowledge. Scand J For Res. 2014;29:56-70.

7. Nilsson M, Staal Wästerlund D, Wahlberg O, Eriksson LO. Forest planning in a Swedish company - a knowledge management analysis of forest information. Silva Fenn. 2012;46(5):717-31.

8. Hiltunen V, Kurttila M, Pykäläinen J. Strengthening top-level guidance in geographically hierarchical large scale forest planning: experiences from the Finnish state forests. Silva Fenn. 2012;46(4): 539-54.

9. Iverson D, Alston R. The genesis of FORPLAN: a historical and analytical review of Forest Service planning models, General technical report INT-214. Ogden: USDA Forest Service Intermountain Res. Sta; 1986.

10. Navon D. Timber Ram: a long-range planning method for commercial timber lands under multiple-use management, USDA Forest Service research paper PSW-70. Berkeley, CA: USDA Pacific Southwest Research Station; 1971.

11. Johnson K, Jones D. A user's guide to multiple use sustained yield resource scheduling calculation (MUSYC), USDA. Forest Service Timber Management: Fort Collins; 1979.

12. USDA Forest Service. Decision support systems for ecosystem management: an evaluation of existing systems, USDA Forest Service Rocky Mountain Forest and Range Experiment Station General Technical Report RM-GTR-296, Fort Collins, 1997.

13. USDA Forest Service, Washington DC National Office, Land Management Planning Handbook, 2012. [Online]. Available: http://www.fs.usda.gov/Internet/FSE_DOCUMENTS/ stelprdb5409973.pdf. Accessed 10 Dec 2014.

14. Nelson J. Forest-level models and challenges for their successful application. Can J For Res. 2003;33(3):422-9.

15. Hoganson H, Vanderschaaf C, and O'Hara T. Insights from harvest scheduling applications in Minnesota, University of Minnesota Department of Forest Resources Staff Paper 227, St Paul, MN, 2014. $10 \mathrm{pp}$.

16. Walker J. ECHO: solution technique for nonlinear economic harvest optimization. In: Meadows J, Bare B, Ware K, Row C, editors. Systems analysis and forest resource management. Society of American Foresters: Washington; 1976. p. 172-8.

17. Walker J. Traditional sustained yield management: problems and alternatives. For Chron. 1990;66(1):20-4.
18. Hrubes R, and Navon D. Application of linear programing to downward sloping demand problems in timber production, USDA Forest Serv. Res. Note PSW-315, Pacific Southwest Forest and Range Exp. Stn., Berkeley, CA, 1976.

19. Duloy J, Norton R. Prices and incomes in linear programming models. Am J Agric Econ. 1975;57(4):591-600.

20. Hoganson H, Rose D. A simulation approach for optimal timber management scheduling. For Sci. 1984;30:220-38.

21. Davis L, Johnson K. Forest management. 3rd ed. New York: McGraw-Hill; 1987. p. 790.

22. Paredes V, Brodie J. Activity analysis in forest planning. For Sci. 1988;34(1):3-18.

23. Newman D. Forestry's golden rule and the development of the optimal forest rotation literature. J For Econ. 2002;8(1):5-27.

24. Paredes V, Brodie J. Land value and the linkage between stand and forest level analyses. Land Econ. 1989;65(2):158-66.

25. USDA Forest Service. Final environmental impact statement: forest plan revision: Chippewa and Superior National Forests. Milwaukee: USDA Forest Service Eastern Region; 2004. p. 1732.

26. Lappi J. JLP: A linear programming package for management planning, The Finnish Forest Research Institute Research Paper 414. Helsinki: The Finnish Forest Research Institute; 1992. p. 134.

27. Lappi J, Nuutinen T, and Siitonen M. A linear programming software for multi-level forest management planning, in Proceedings of the 1994 Symposium on System analysis in Forest Resources, Management Systems for a Global Economy with global resource concerns, September 6-9, 1994, Asilomar Conference Center, Pacific Grove, California, College of Forestry, Oregon State Univ., Corvallis, OR., 1995.

28. Dantzig G, Van Slyke R. Generalized upper bounding technques. J Comput Syst Sci. 1967;1:213-2226.

29. Siitonen M, Anola-Pukkila A, Haara A, et al. (eds). MELA handbook 2000 edition, 2001. [Online]. Available: http://mela2.metla.fi/ mela/julkaisut/oppaat/mela2000.pdf. Accessed 10 Dec 2014.

30. Weintraub A, Cholaky A. A hierarchical approach to forest planning. For Sci. 1991;37(2):439-60.

31. Pittman S, Bare B, Briggs D. Hierarchical production planning in forestry using price-directed decomposition. Can J For Res. 2007;37(10):2010-21.

32. Bettinger P, Chung W. The key literature of, and trends in, forestlevel management planning in North America, 1950-2001. Int For Rev. 2004;6(1):40-50.

33. Weintraub A, Romero C. Operations research models and the management of agricultural and forestry resources: a review and comparison. Interfaces. 2006;36(5):446-57.

34. Gunn E. Some perspectives on strategic forest management models and the forest products supply chain. INFOR Inf Syst Oper Res. 2009;47(3):261-72.

35. Paradis G, LeBel L, D'Amours S, Bouchard M. On the risk of systematic drift under incoherent hierarchical forest management planning. Can J For Res. 2013;43(5):480-92.

36. Beaudoin D, Frayret J, LeBel L. Hierarchical forest management with anticipation: an application to tactical-operational planning integration. Can J For Res. 2008;38(8):2198-211.

37. Tóth S, McDill M, Konnyu N, George S. Testing the use of lazy constraints in solving srea-based adjacency formulations of harvest scheduling models. For Sci. 2013;59(2):57-176. Thorough testing and promising results for utilizing a specialized operations research method for addressing large problems.

38. McNaughton A, Ryan D. Adjacency branches used to optimize forest harvesting subject to area restrictions on clearfell. For Sci. 2008;54(4):442-54.

39. Tóth S, McDill M, Rebain S. Finding the efficient frontier of a bicriteria, spatially explicit, harvest scheduling problem. For Sci. 2006;52(1):93-107. 
40. Tóth S, McDill M. Finding efficient harvest schedules under three conflicting objectives. For Sci. 2009;55(2):117-31.

41. Hoganson H, and Kapple D. DTRAN version 1.0: A multi-market timber supply model, College of Natural Resources and Agricultural Exp. Sta., Dept. of Forest Resources Staff Paper Series Report No. 81, University of Minnesota, St Paul, MN, 1991, 64 pp.

42. Jaakko Pöyry Consulting, Inc. Generic environmental impact statement on timber harvesting and forest management in Minnesota. Tarrytown: Jaako Pöyry Consulting, Inc; 1994.

43. Lappi J, Lempinen R. A linear programming algorithm and software for forest-level planning problems including factories. Scand $\mathrm{J}$ For Res. 2014;29(supplement 1):178-84. Uses upper bound techniques to overcome model size considerations while also addressing numerous wood shipment options.

44. Lyon K, Sedjo R. An optimal control theory model to estimate the regional long-term supply of timber. For Sci. 1983;29:798-812.

45. Latta G, Sjølie H, Solberg B. A review of recent developments and applications of partial equilibrium intertemproal models of the forest sector. J For Econ. 2013;19(4):350-60.

46. Kong J, Rönnqvist M, Frisk M. Using mixed integer programming models to synchronously determine production levels and market prices in an integrated market for roundwood and forest biomass. Ann Oper Res. 2013. doi:10.1007/s10479-013-1450-0.

47. Frisk M, Göthe-Lundgren M, Jörnsten K, Rönnqvist M. Cost allocation in collaborative forest transportation. Eur J Oper Res. 2010;205(2):448-58.

48. Guajardo M, Rönnqvist M. Operations research models for coalition structure in collaborative logistics. Eur J Oper Res. 2015;240(1):147-59.

49. Carlsson D, Rönnqvist M. Backhauling in forest transportation: models, methods, and practical usage. Can J For Res. 2007;37: 2612-23.

50. Burkhart H, Stuck R, Leuschner W, Reynolds M. Allocating inventory resources for multiple-use planning. Can J For Res. 1978;8(1): 100-10.

51. Gilabert H, McDill M. Optimizing inventory and yield data collection for forest management planning. For Sci. 2010;56:578-91. Expands analyses to recognize importance of integrating forest inventory efforts with forest management planning.

52. Kangas A, Hurttala H, Mäkinen H, Lappi J. Estimating the value of wood quality information in constrained optimization. Can J For Res. 2012;42:1347-58.

53. Duvemo K, Lämås T, Eriksson L, Wikström P. Introducing costplus-loss analysis into a hierarchical forestry planning environment. Ann Oper Res. 2012;219(1):415-31.

54. Eriksson L. Planning under uncertainty at the forest level: a systems approach. Scand J For Res. 2006;21:111-7.

55. Boychuk D, Martell D. A multistage stochastic programming model for sustainable forest-level timber supply under risk of fire. For Sci. 1996;42(1):10-26.

56. Hoganson H, Rose D. A model for recognizing forestwide risk in timber management scheduling. For Sci. 1987;33(2):268-82.

57. Hoganson $\mathrm{H}$, and Smith E. Recognizing uncertainty and the sequential nature of decisions in forest management planning, in: Forestry on the frontier: proceedings of the 1989 Society of
American Foresters National Convention, SAF publication 89-02, Spokane, Washington, 1990.

58. Palma C, Nelson J. A robust optimization approach protected harvest scheduling decisions against uncertainty. Can J For Res. 2009;39(2):342-55.

59. Palma C, Nelson J. A robust model for protecting road-building and harvest-scheduling decisions from timber estimate errors. For Sci. 2014;60(1):137-48.

60. Reynolds K. Integrated decision support for sustainable forest management in the United States: fact or fiction? Comput Electron Agric. 2005;49(1):6-23.

61. Menzel S, Buchecker M, Nordström E, et al. Decision support systems in forest management: requirements from a participatory planning perspective. Eur J For Res. 2012;1367-1379.

62. Power D, Sharda R. Model-driven decision support systems: concepts and research directions. Decis Support Syst. 2007;43(3): 1044-61.

63. Muys B, Hynynen J, Palahi M, et al. Simulation tools for decision support to adaptive forest management in Europe. For Syst. 2010;3(4):86-99.

64. Pukkala T. Dealing with ecological objectives in the Monsu planning system. Silva Lusit. 2004;12(special):1-15.

65. Rasinmäki J, Mäkinen A, Kalliovirta J. SIMO adaptable simulation and optimization for forest management planning. Comput Electron Agric. 2009;66(1):76-84.

66. ForestDSS. Community of Practice, 2013. [Online]. Available: http://www.forestdss.org/CoP/. Accessed 9 Dec 2014.

67. Packalen T, Marques A, Rasinmäki J, et al. A brief overview of forest management decision support systems (FMDSS) listed in the FORSYS wiki. For Syst. 2013;22(2):263-9.

68. ForestDSS, Agflor, 2014. [Online]. Available: http://www. forestdss.org/wiki/index.php?title=Agflor. Accessed 10 Dec 2014.

69. Forest Biometrics Research Institute, Forest Projection and Planning System (FPS), [Online]. Available: Forest Projection and Planning System (FPS)https://forestbiometrics.com/software/ fps/. Accessed 10 Dec 2014.

70. National Council for Air and Stream Improvement, HabPlan, 2012 [Online]. Available: www.ncasi2.org/projects/habplan/. Accessed 10 Dec 2014.

71. Wikström P, Edenius L, Elfving B, et al. The Heureka forestry decision support system: an overview. Math Comput For Nat Res Sci. 2011;3(2):87-94.

72. Swedish University of Agricultural Sciences, Heureka, 2014. [Online]. Available: http://heurekaslu.org/wiki/Heureka Wiki. Accessed 10 Dec 2014. Summarizes a thorough and leading effort for a comprehensive decsion support system in forest management.

73. ForestDDS, SADfLOR, 2014. [Online]. Available: www.forestdss. org/wiki/index.php?title=SADfLOR. Accessed 10 Dec 2014.

74. AIMMS. Modeling the forest: Ontario's Ministry of Natural Resources takes us through decades of effective forest management. http://techblog.aimms.com/2014/04/01/modelling-theforest-ontarios-ministry-of-natural-resources-takes-us-throughdecades-of-effective-forest-management. Accessed 22 Dec 2014.

75. Remsoft, Remsoft forestry, 2014. [Online]. Available: www. remsoft.com/forestry.php. Accessed 10 Dec 2014. 